\title{
Expanding the motivations for altruism: A philosophical perspective
}

\author{
JULIAN FRIEDLAND ${ }^{1 *}$ AND BENJAMIN M. COLE ${ }^{2}$ \\ ${ }^{1}$ Department of Strategic Management and Public Policy, The School of Business, The George Washington University, \\ Washington, DC, 20052, USA \\ ${ }^{2}$ Department of Management Systems, Schools of Business Administration, Fordham University, New York, NY, \\ 10019, USA
}

\begin{abstract}
Summary We argue that attempts to extrapolate moral motives for non-egoistic behavior in organizational behavior often interpret results empathically or deontically, while leaving other moral motivational frames, such as the utilitarian and virtue ethical, under-examined. We encourage the creation of experimental measures to distinguish various philosophical frames. Copyright (C) 2013 John Wiley \& Sons, Ltd.
\end{abstract}

Keywords: altruism; empathic; deontic; utilitarian; virtue ethical

\section{Introduction}

Classically, the literature has relied on two primary lenses to explain the drivers of seeming altruistic behaviors: an empathy-induced explanation (e.g., Batson, 1995) originating in social psychology and a deontic justice/ fairness perspective (e.g., Folger, 2001) originating in organizational behavior (and informed by social psychology). In this incubator, we argue that altruism need not be empathically-induced or deontically-motivated. Drawing primarily from the philosophy literature, we argue that moral motivations may also be utilitarian and/or virtue ethical in nature. Although ethical philosophers do not make explanatory claims about human behavior, they do make arguments about the nature of the good. Some people will naturally follow ethical norms unthinkingly in an internalized fashion; others will do so more conscientiously. The latter is what makes moral progress possible. We call for broader research and more specified measures in order to sort out the various moral motivations for altruism, and possibly the extent to which they may correlate with higher levels of moral development.

\section{Must Altruism be Empathic?}

The social psychological literature challenging the universal egoism thesis of human motivation argues that genuinely altruistic actions do, in fact, exist. Batson's theoretical model depicts altruism as occurring when two sensory conditions are satisfied at once, namely, (i) the perception of a need and (ii) the valuing of another's welfare (Batson, 2011). It is argued that the individual who participates in altruistic behavior is placing the needs and welfare of the others above those of the self, which results in the observed prosocial (i.e., helping) behavior. In fact, research indicates that persons will choose to even undergo pain, i.e., electric shock, in order to attend to strangers in distress (Batson, 1995).

\footnotetext{
*Correspondence to: Julian Friedland, Department of Strategic Management and Public Policy, The School of Business, The George Washington University, Washington, DC, 20052, USA. E-mail: jfriedland@gwu.edu
} 
One could characterize this social psychological perspective as an emotivist account of altruism as motivated by the experience of empathy. Batson's empirical research on humans (Batson et al., 1989) is further buttressed by evidence of empathic behavior in other species such as dogs, primates, dolphins, and elephants as well as on how infant humans come to learn to care about how others feel. Surely, empathy must be part of a complete account of the moral motivations for altruism. At the same time, however, there exists a growing sociobiological literature suggesting that altruism has become biochemically embedded as an adaptive trait in myriad species defined as eusocial (Nowak, Tarnita, \& Wilson, 2010). Eusociality exists even in insects such as ants (Nowak et al., 2010), for which there is little if any indication of emotional experience.

Explanatory accounts on the emotive nature of altruistic motivation do not address non-empathic moral motivations that may be more dispassionate and philosophical. Kohlberg's theory of moral development suggests that persons who reach the post-conventional level of moral development behave according to stage-five utilitarian or stage-six deontic principles (Kohlberg, 1971), requiring them not to preference their own position over those of others. As such, they behave altruistically on a regular basis, doing so for purely philosophical reasons. Kohlberg (1984) estimates that only about 20 percent of adults actually reach this level of cognitive development. Although Kohlberg (1984) relied on placing people in hypothetical moral dilemmas and asking them a series of questions on how and why they would behave in those situations, he did not seek to prove that those individuals actually do behave that way in practice. It might be that all altruistic behavior is, in fact, triggered by empathic motivation. There are, however, good reasons not to hold this view.

One such reason is the frequency of so-called passive altruism, which is taken-for-granted behavior that when isolated would be categorized as altruistic in nature, yet broadly goes unnoticed when observed in daily life (Stout, 2010, p. 45-71). The overwhelming majority of individuals are not tempted to steal the money out of a homeless beggar's hat or to loot abandoned stores after a flood. Similarly, most people prefer to wait until they reach a waste receptacle to discard their trash rather than simply litter. Yet, we do not marvel at these mundane examples of altruism. Rather, we take them for granted, much as we do the force of gravity (Stout, 2010). Avoidance of empathic pain for the homeless or esthetic displeasure at a littered sidewalk may at times be at work to some degree, but in countless ordinary occurrences, passive altruism is not caused by negative emotional pressures because there is no temptation to act otherwise nor countervailing empathic emotions to keep us in line.

Still, social norms and laws do reinforce and internalize this behavior. And moral training may employ empathic pain and pleasure at lower levels of moral maturity. Eventually, though, those empathic training wheels are no longer needed at higher levels of moral maturation. A child may require an empathic trigger to understand why it is wrong to steal, but as the child becomes morally mature, he/she will no longer rely on that empathic trigger to refrain from stealing. Rather, it scarcely even occurs to the child that he/she could choose to steal. Similarly, in ordinary cases of mundane active altruism, a morally mature adult may pick up someone else's litter or drop a small sum of money into the hat of a sleeping homeless person without feeling emotive satisfaction. In the case of benefitting the homeless, there is at least a minimal degree of concern for the person's welfare, but this may not be a strong enough empathic effect to fully motivate the action. In fact, there is evidence that people may not do what they think is actually fair while empathically motivated (Batson, Klein, Highberger, \& Shaw, 1995). This suggests that empathic stimuli may at times cloud moral judgment. Consequently, morally mature people will behave altruistically as a matter of course, simply because they know it to be right, not because they get a rush of emotive satisfaction.

What is more, the empathic motivation account of altruism cannot explain impersonal cases in which there is no one to feel empathy for, namely, when picking up the litter left behind by others on the street. Such cases exemplify dispassionate ethical behavior that could be the result of sophisticated moral frames or internalized ethical intuitions (Huemer, 2005). We pick up the litter because we reason or sense it to be the right thing to do; not because we feel for the plight of anyone potentially burdened by a littered sidewalk. 


\section{Altruism and Moral Reasoning}

There is substantial organizational behavior research indicating that persons will behave self-sacrificially according to internalized moral norms (Kahneman, Knetsch, \& Thaler, 1986; Turillo, Folger, Lavelle, Umphress, \& Gee, 2002). Although the behavior recorded in these studies is not fully altruistic, as subjects are compelled to make an economic choice and only have limited number of options, it is nevertheless non-egoistic. Furthermore, it should be noted that in such cases, subjects are not necessarily motivated by the expectation of empathic pleasure and/or the avoidance of empathic pain. This is because the interactions in much of this research are carried out in entirely impersonal settings devoid of any personal knowledge or physical contact. So the subjects have no emotional investment in the other participants, who may not even exist as genuine persons given that they are neither seen nor heard and merely participating in an online investment game.

In the widely cited Kahneman et al. (1986) "dictator game" study (replicated by Turillo et al. (2002) and cited by Cropanzano, Goldman, and Folger (2003)), one person (the dictator) is offered two possible payouts—one that earns the dictator $\$ 5$ and one that earns $\$ 6$. In the end, 74 percent of the participants choose the $\$ 5$ option, which allowed them to give $\$ 5$ to a participant who had taken $\$ 10-\$ 10$ split of a $\$ 20$ pot of money in a previous round and to not give anything to a participant who had demanded an \$18-\$2 split that favored him- or herself; the $\$ 6$ payout option would have given an additional \$6 to the one who had demanded the \$18-\$2 split. The decision to forgo the $\$ 1$ higher payout is interpreted as a deontic justice stand on the part of the dictator, who is supposedly "rewarding" those who acted more fairly in a previous round and "punishing" those who acted more unfairly. This and other similar studies provide convincing evidence that subjects are motivated by moral norms. The organizational behavior literature in which this research originates has interpreted such motivations as grounded in deontic justice (Folger, 2001).

Despite this logical extrapolation of moral motivation in non-empathy-inducing settings, it is important to note that an alternative motivation - a utilitarian one-would have yielded the same decision to forgo the same dollar as a deontic one. Viewing the pocketed monies across both periods, the $\$ 5$ payout option would yield $\$ 38$ to all parties - $\$ 18$ for the unfair person, $\$ 15$ to the fair person, and $\$ 5$ for the dictator, whereas the $\$ 6$ payout option would yield $\$ 40$ to all parties $-\$ 24$ total across both rounds for the unfair person, $\$ 10$ for the fair person, and $\$ 6$ for the dictator. The first "fairer" option, chosen by 74 percent of subjects, separates the first two subjects by only $\$ 3$, while the "unfair" distribution provides the first subject with nearly 2.5 times more than the second. The extra dollar the dictator can pocket for the "unfair" distribution is negligible when the subject is trying to maximize value for all parties equally - a manifestation of a utilitarian moral frame. The fairer distribution has the added utilitarian benefit of rewarding previous fair behavior and punishing previous unfair behavior (though interestingly, selfishness in the first round mathematically wins out in both cases here even after round 2). Thus, one cannot necessarily extrapolate deontic or non-utilitarian motivations for the decision to take a lower $\$ 5$ payout by selecting the "fairer" distribution. It may not be possible to modify this particular experiment to clearly distinguish between deontic and utilitarian moral frames given that the unfair option is placed in opposition to a fairer result that may be motivated by either or both moral frames, but as currently constructed, this classic game cannot distinguish the two.

This economic experiment has been modified to extrapolate more nuanced views of the motives involved, but with similar levels of (un)success when viewed from a philosophical perspective. One such modification allows the dictator to hold $\$ 20$ and be tasked with the hypothetical choice of either dividing it equally or keeping $\$ 18$ and giving $\$ 2$ to the other. Three-fourths of subjects chose to divide equally in this setup (Kahneman et al., 1986). In several follow-on studies in which the stakes were made real and the action set made less discrete, 60 percent of subjects transfer a mean allocation of roughly 20 percent of the endowment (Camerer, 2003). In a further experiment, six different factors were added to increase the social distance between the participants including concealing the dictator's decision from the experimenters and allocating the money by lottery so that those receiving even nothing from dictators did not know if the dictators had received anything themselves. When all six factors were present, 65 percent of dictators kept all the money for themselves (Hoffman, McCabe, Shachat, \& Smith, 1994). 
To label the 65 percent who chose to give nothing as "unfair" or "unjust" strains the definition of justice as fairness, because none of the recipients earned or were promised anything to begin with. As such, it makes little sense to assume deontic moral framing is necessarily at work here. Rather, it seems as if 35 percent of subjects displayed sheer altruism (as magnanimous dictators) in choosing to consider the interests of others besides themselves. Hence, this suggests a motivation further from deontology and closer to utilitarianism, which explicitly defines good actions as considering everyone's interests equally, or virtue ethics, which conceives the good as the continual pursuit of self-realization in ways that are habit-forming and allow the individual to make correct decisions into the future with progressively less discomfort (Aristotle, 2011). It should be noted that in the field of philosophy, altruism is more closely associated with utilitarianism than with deontology, for there is no explicit deontic obligation to behave altruistically.

\section{Conclusion}

If we are to accept the growing empirical evidence against homo economicus indicating that persons exhibit altruism in myriad ordinary instances, then we must take a wider view of that motivation beyond the empathic models of the economic and social psychological literature and the deontic justice models of the organizational behavior literature. Furthermore, as evidenced in the dictator game scenarios discussed, moral frames tend to overlap philosophically. This makes it difficult to accurately extrapolate moral motivations for altruism and for ethical behavior generally. Therefore, in this incubator, we recommend devising and validating experimental measures to distinguish various philosophical frames, rather than relying on extrapolation of moral motives. Examples of questions that could discern utilitarian from deontic from virtue ethical are: (U) "The end result of our actions is more important than how we go about doing them. Do you agree?"; (D) "No one should have to suffer for the benefit of others. Do you agree?"; (VE) "Your actions are only good if they also make you a better person. Do you agree?" Better measurement, rather than theoretical conjecture, can improve our ability to pinpoint the drivers of altruistic behavior.

\section{Author biographies}

Julian Friedland is a visiting assistant professor of Strategic Management and Public Policy at the George Washington University School of Business. He obtained his $\mathrm{PhD}$ in Philosophy from the University of Paris 1—Panthéon Sorbonne. His research focuses on moral epistemology and the nature of positive professional duty.

Benjamin M. Cole is an assistant professor of Management Systems at the Gabelli School of Business at Fordham University. His research interests can be divided into three areas: the social construction of innovation, social influences in regulatory and self-regulatory settings, and moral / cultural lenses in organizational settings.

\section{References}

Aristotle. (2011). Aristotle's Nicomachean Ethics. Chicago, IL: University of Chicago Press.

Batson, C. D. (1995). Prosocial motivation: why do we help others? In A. Tesser (Ed.), Advanced Social Psychology (pp. 332-381). Boston, MA: McGraw-Hill.

Batson, C. D. (2011). Altruism in Humans. New York, NY: Oxford University Press.

Batson, C. D., Batson, J. G., Griffitt, C. A., Barrientos, S., Brandt, J. R., Sprengelmeyer, P., \& Bayly, M. J. (1989). Negative-state relief and the empathy-altruism hypothesis. Journal of Personality and Social Psychology, 56(6), 922-933.

Batson, C. D., Klein, T. R., Highberger, L., \& Shaw, L. L. (1995). Immorality from empathy-induced altruism: when compassion and justice conflict. Journal of Personality and Social Psychology, 68(6), 1042-1054.

Camerer, C. F. (2003). Behavioral Game Theory. New York: Russell Sage Foundation. 
Cropanzano, R., Goldman, B., \& Folger, R. (2003). Deontic justice: the role of moral principles in workplace fairness. Journal of Organizational Behavior, 24, 1019-1024.

Folger, R. (2001). Fairness as deonance. In S. W. Gilliland, D. D. Steiner, \& D. P. Skarlicki (Eds.), Theoretical and Cultural Perspectives on Organizational Justice (pp. 3-31). Greenwich, CT: Information Age.

Hoffman, E., McCabe, K., Shachat, K., \& Smith, V. (1994). Preference, property rights and anonymity in bargaining games. Games and Economic Behavior, 7, 346-380.

Huemer, M. (2005). Ethical Intuitionism. New York, NY: Palgrave Macmillan.

Kahneman, D., Knetsch, J. L., \& Thaler, R. H. (1986). Fairness and the assumptions of economics. Journal of Business, 59, S285-S300.

Kohlberg, L. (1971). From is to ought: How to commit the naturalistic fallacy and get away with it in the study of moral development. In T. Mischel (Ed.), Cognitive Development and Epistemology (pp. 151-235). New York: Academic Press.

Kohlberg, L. (1984). Essays in Moral Development: Vol. 2. The Psychology of Moral Development. New York, NY: Harper \& Row. Nowak, M. A., Tarnita, C. E., \& Wilson, E. O. (2010). The evolution of eusociality. Nature, 466(7310), $1057-1062$.

Stout, L. (2010). Cultivating Conscience: How Good Laws Make Good People. Princeton, NJ: Princeton University Press.

Turillo, C. J., Folger, R., Lavelle, J. J., Umphress, E. E., \& Gee, J. O. (2002). Is virtue its own reward? Self-sacrificial decisions for the sake of fairness. Organizational Behavior and Human Decision Processes, 89, 839-865. 